\title{
New Materials: Natural Elements and the Body in Screendance
}

Sylvie Vitaglione, New York University

\begin{abstract}
This article explores the practice of shooting on location in screendance advocating for a practice that explores the concept of material specificity in order to create grounded conceptual works. In order to metaphorically and literally ground the dancing body, this article examines the crucial dichotomy between intervention in sites and integration of sites in order to understand exactly what stance screendance takes on its settings. In other words, what do artists take from the site and what do they bring to it? I begin by examining various definitions of site-specificity. By surveying theories and practices surrounding the artistic treatments of locations, my aim is to highlight the choreographic and cinematic techniques that connect the dancing body to the environment. I argue that through the use of natural elements these films articulate a version of site-specificity deeply connected to the materiality of each location rather than to its geography or history.
\end{abstract}

Keywords: site-specificity, land art, material specificity, location shooting, screendance

Screendance is concerned with the body. As the exploration of the friction between the corporeal and the technological, between the live and the recorded, between the still and the mobile continues, in recent years the practice has shifted to new grounds: screendance has become concerned with space. ${ }^{1}$ The camera and its accompanying gear have pushed dancing bodies outside to explore sites and surfaces beyond the studio and the stage. Our sprung wood floors and smooth Marley now quasi-obsolete onscreen, the screendance body takes root outdoors. ${ }^{2}$ Shooting on-location has not only become a possibility, it has become the default option. The vast majority of films in circulation at festivals take place outside and most film synopses begin with a description of a physical location. While landscapes seem to offer a practical solution to finding large spaces to fit tight budgets, the recurrence of particular types of natural spaces without a conceptual backbone becomes cliché. After all, what does that beautiful sunset on the beach have to do with grand-jetés? 
In her article analyzing the films of Thierry de Mey, Sophie Walon claims that "the cinematic possibility of relocating theatrical works to original sites appears to be one of the most efficient ways of enabling screendance artists to make a creative dance film that is emancipated from being a mere dance recording." ${ }^{3}$ While it is true that the use of sites has generated a number of creative and memorable films, the simple relocation of a dance does not in itself suffice to create an original work with integrity. Screendance utilizes sites in different ways and not every film shot on location can be called site-specific. Numerous films treat landscapes as visual backdrops, much like in a fashion photo-shoot, because it "looks cool." The outdoor location provides ample space for movement and adds depth to the typically frontal staging but overall its use remains within a theatrical tradition. The camera stays put while the dancers face it, much like they would an audience. For example, in Luc Riolon's Aunis (1994), Jacques Garnier's choreography is set on a beach in Normandy where three men dance on a thin white stage set in the sand. While their costumes move in the wind and the waves in the background add movement to the film, the piece could very well be set anywhere with a flat surface and sunlight. Landscape here provides a background for the body while the camera alternates between three safe medium shots. Choreography in such cases does not aim to relate to the site but rather lands on it, in a sort of "Plop Art" as Noémie Lafrance would say. ${ }^{4}$

In order to metaphorically and literally ground the dancing body, this article explores the crucial dichotomy between intervention in sites and integration of sites in order to understand exactly what stance screendance takes on its settings. In other words, what do artists take from the site and what do they bring to it? I begin by examining various definitions of site-specificity. By providing a survey of the theories and practices surrounding the artistic treatments of locations, my aim is to highlight the choreographic and cinematic techniques that connect the dancing body to the environment. I argue that through the use of natural elements these films articulate a version of site-specificity deeply connected to the materiality of each location rather than to its geography or history.

Screendance makers are familiar with the term site-specific yet the numerous variations on it suggest that the scope of possibilities when shooting on-location is broader than we might expect. In her seminal book Dance on Screen, Sherril Dodds observes that these choices of location typically demonstrate a sparse background with minimal set design so as to keep the attention on the dancing body. She notices that the "video dance body is often situated in unexpected locations, but also, in several cases, it is presented within circumstances that are illogical and peculiar." ${ }^{5}$ For Dodds, the lure of the landscape is primarily a way to focus on the body by reducing the clutter in the frame and seeking open spaces to move in. While visually the result can be striking, conceptually the lack of narrative connections between the dance and the site can make films weak due to incongruous choreography. 
The rapport between site, body, and camera lens is often referred to as a dialogue, one where the artist should be prepared to listen, respond, and improvise. For Heike Salzer "shooting dance on sites has an exciting side effect, it is uncontrollable; the weather changes, animals or objects [...] appear. These unexpected moments offer the chance for a dialogue between the environment, the dancers, and the filmmaker." ${ }^{\prime 6}$ The presence of uncontrollable factors in the environment has the benefit of literally pushing artists out of their comfort zone and potentially generating a productive collaboration. Ana Baer speaks of "situational screendances" where the narrative develops out of the situation encountered in the location. ${ }^{7}$ Both of these approaches to shooting on-site stress the need to be ready to catch something as it comes, filming almost in a documentary-style and turning movement-making into an exercise in improvisation. What Baer and Salzer fail to explain is the way through which the link between the body and its surroundings is established; beyond simply being in the right place at the right time, how does a dance filmmaker make a piece site-specific?

Kyra Norman has brought to our attention several choreographers for whom work is born out of "sincere attention to place in the moment of recording" and suggests that by being "in and out of place," these artists manage to stay physically engaged with space while making screendance. ${ }^{8}$ She distinguishes between inhabiting and occupying a place suggesting that a traditional film crew will simply take hold of the space around them and temporarily occupy it. Inhabiting a place for Norman is to "engage space directly through the body," to focus "attention to active vision and responsiveness to place." ${ }^{\prime 9}$ The distinction she makes underlines the importance of spending time on the site in order to find a way to relate to it and to respond to it. However, the concept of "engaging space through the body" remains vague and open to many interpretations. Again we must ask, how does one occupy place?

In her manual Making Video Dance, Katrina McPherson addresses the selection of locations in dance films as though shooting outdoors is a given. She warns about the incompatibility between dance and filming on location and urges filmmakers not to forget about the dance: "frequently, whilst featuring interesting locations, the work seems to lack any really significant choreographic content."10 She emphasizes the importance of creating a dance that seems appropriate for the space, so that bodies do not seem "out of place" and suggests strategies for integrating the landscape into the choreography. ${ }^{11}$ For example, she proposes that by "having the dancer move around and through, and even touch objects, you will create the feeling that their actions belong in the location." ${ }^{12}$ McPherson's suggestion to have the dancer physically come in contact with the setting is by far the most practical and approachable, emphasizing the need for the viewer to not only see a connection between the dancer and the space but to feel the environment and to relate to it through the performer's body. For McPherson rendering touch creates a dance "in place." With what "objects" might a dancer come into contact with and what might 
they signify within the film? Does touch suffice to create site-specificity for screendance?

None of the authors above explicitly utilize the label site-specific yet they are all theorizing ways of engaging with location in screendance. While the term is by no means foreign to the field, it remains somewhat difficult to apply simultaneously to the contexts of both dance and film. My purpose here is to first clarify conceptions of site-specificity as originally articulated in relation to Land Art, and second, to propose a new concept that emphasizes materiality in order to theorize screendance shot on location.

\section{Defining Site-Specificity}

The term site-specific emerged in the early 1970s in the US and was adopted in Europe in the 1980s. While numerous US-based choreographers such as Trisha Brown, Anna Halprin, and Meredith Monk had taken dance outdoors in the 1960s, the term sitespecific was hardly in circulation in the dance world. Instead it came from the world of visual arts, combining the fashion for minimalism with large-scale sculpture. 1968 marks the year of shifting attitudes toward environmental issues as presented in the Earthworks exhibition in New York. Land Art emerged as a type of sculptural practice drawing from architecture and landscape design, often utilizing photography and film to record the traces left in distant locations. As an attempt to de-materialize the art object within the institution of the gallery, these works presented a variety of ways for art to "take place" in the landscape.

In her 1979 essay "Sculpture in the Expanded Field," art critic and theorist Rosalind Krauss questions the validity of the term "sculpture" for these works. While she does not adopt the term Land Art she does coin "marked sites" to describe Robert Smithson's Spiral Jetty (1970) and Michael Heizer's Double Negative (1969) in addition to work by Richard Serra, Robert Morris, Carl Andre, Dennis Oppenheim, Nancy Holt, and George Trakis. She stipulates that "in addition to actual physical manipulations of sites, this term also refers to other forms of marking. These might operate through the application of impermanent marks-Heizer's Depressions, Oppenheim's Time Lines, or De Maria's Mile Long Drawing, for example-or through the use of photography." ${ }^{13}$ This mention of the temporality of the mark and the need to document it through a visual medium comes close to the considerations of ephemerality and permanence often encountered in screendance.

In this sense, one definition of site-specific art equals a piece which is created and installed on-site and typically necessitates the presence of the viewer in order to fully experience the materiality of the work. Art historian Miwon Kwon explains that "sitespecific work in its earliest formation, then, focused on establishing an inextricable, indivisible relationship between the work and its site, and demanded the physical 
presence of the viewer for the work's completion." ${ }^{14}$ Of course this would only be possible if the viewer had the means and foreknowledge to be in the right place at the right time. Therefore, through the use of photographs and films, as well as materials such as rocks, twigs, and dirt collected on-site, artists found ways to bring traces of the landscape back to the gallery.

If Land Art aims to de-materialize itself as an art object, to produce works in nature that are not available for purchase, what type of imprint do they aim to leave on the land? As sculpture, one would assume a certain weight and fixity in place, but as works in nature these alterations are necessarily subject to weathering and the movement already present in the site. Writing in 1989, Richard Serra explains:

Site-specific works deal with the environmental components of given places. The scale, size, and location of site-specific works are determined by the topography of the site, whether it be urban or landscape or architectural enclosure. The works become part of the site and restructure both conceptually and perceptually the organization of the site. ${ }^{15}$

Serra's definition does not mention how permanent this restructuring of the site is, and yet his most notorious claim in reference to his piece Tilted Arc (1981) in New York City is that "to remove the work is to destroy it." In a similar vein, curator Michael Lailach in his definition of site-specificity in Land Art suggests that "the artists conceive the works for particular settings and create them on site. Thereby they alter the location's surface, structure, and materiality, and inscribe themselves in its memory." ${ }^{16}$ Once more, while Lailach points to the modification of the surface of the site and the inscription of the piece into the site's history, he does not consider how this physical impact shifts over time, how nature might re-write this dent made on its surface.

According to Ben Tufnell, Land Art "encompasses the scarring of the landscape, the ecological reclamation of industrially devastated terrain, an impulse towards change and permanence and an attitude of respect, a desire to "leave no trace."'17 This spectrum presents a more diverse picture as it highlights the many possible stances towards landscape within the umbrella term "Land Art." It also suggests a shift in the term's scope, the label "specific" now expanding to mean much more (or less as is sometimes the case). Kwon suggests that the original rootedness of site-specific art in the 1960s and 1970s has now given way to more mobile and unhinged work. In other words, whereas site-specific art used to mean that the tangible physical work could not exist in any other place and would risk being destroyed if moved (as in the sculptures of Richard Serra and Robert Smithson's Spiral Jetty), its definition has since shifted towards "site as predominantly an intertextually coordinated, multiply located, discursive field of operation." ${ }^{18}$ What Kwon calls an intertextual relationship is in fact a complex, at times less visible, link to landscape. She informs us that in "art practices of the past thirty years the operative definition of the site has been transformed from a 
physical location-grounded, fixed, actual-to a discursive vector-ungrounded, fluid, virtual." ${ }^{19}$ Rather than a concrete physical relationship between land and art, the new model is "not a map but an itinerary, a fragmentary sequence of events and actions through spaces, that is, a nomadic narrative whose path is articulated by the passage of the artist." ${ }^{20}$ Whereas once viewers "had to be there" to experience the work and the work itself actually physically "had to be there" to exist, site now filters through in many ways in this more complicated, more "fluid" form of marking the landscape.

This looser application of the term site-specific explains its current presence across multiple artistic disciplines as a label much like "environmentally friendly": often encountered but worthy of skepticism. Within the dance world, the term picked up popularity in the 1980s to refer simply to work not on a proscenium stage, and now constitutes an asset in funding applications. I argue that there is a difference between choreography developed on-site, which could not exist anywhere else, and dance simply located on a site for the sake of a change of scenery. Screendance artists avoid the physical constraints of live performance by producing films, however as they relocate to the outdoors, often to remote locales, they create a temporary imprint on the land with their crew and dancers. In addition, I argue that the recording of movement in space generates a trace in and of the landscape that is inscribed on the image. The ephemeral presence of the dancing bodies is therefore rendered material and semi-permanent through cinema.

The notion of site-specificity in screendance is complicated. Most of the films I consider in this article do not acknowledge their actual location within the film: the setting remains nameless, detached from any particular geographic location. The body is not permanently attached to any particular site and its movement leaves only a temporary trace on the ground. The articulation of site-specificity in these cases has to do more with the connection between the body's movement and the physical attributes of the location: we are in fact speaking of a material-specificity. The film's choreography and cinematography represent the landscape's materiality while the site remains anonymous, its history a deep one to be found somewhere in the dirt, the dust, the rock, and the plants.

\section{Material Specificity}

To determine the intimate beauty of materials: their mass of hidden assets, all this affective space concentrated inside things.

- Gaston Bachelard ${ }^{21}$

Screendance, like Land Art, is concerned with materials in space. As filmmakers move outdoors they are confronted with the environment: its scale, sounds, densities, textures, and temperatures are now brought in front of the lens and against the body. 
These new materials not only trigger new choreography that challenges the dancing body, but when captured on camera they reveal what Walon calls a "new particular world which can only exist in the screendance medium." ${ }^{22}$ Rich textures fill the frame in close-ups while the sounds of wind, water, leaves, and the dancers' breath are heard on the soundtrack.

In order to create material-specific screendance, choreographers and filmmakers need to begin with a material, the way a sculptor does before he/she begins to chisel away at it. From a choreographic standpoint, by starting with a tangible, textured substance, and designing movement for it, one shifts from creating shapes that will register visually to developing motion that comes from a base of sensations. By imagining materials first, the choreographer considers the impact of the material on the range of motion. The choice of costume becomes important to decide whether or not the body should be protected, whether the skin or fabric can take it. New materials push the dancer's abilities and endurance, and can impact the pace and weight shifting of the choreography. Based on the texture's density and give, one may confront the limits of motion within that environment: can one walk in the sand in stilettos, run in knee-high water, crawl naked in gravel or breakdance in the mud?

A material-specific approach to designing screendance would not only generate new types of sensation-based movement but it would also create original haptic films. From the filmmaker's standpoint, in order to render the materiality of the site palpable, the film should include numerous close-ups and medium or long shots of the site without a performer in it. Direct sound with sparse music captures the sense of texture and weight of different materials. Placing the microphone near points of contact between the surface and the dancer helps convey the physical nature of the interaction. Shots that show the environment's impact on the body, the mark it leaves on the skin, the fabric or hair also aid in representing the qualities of the site and give the audience a sense of what it is like to be there. Longer takes and slower editing allow the viewer time to look beyond the body in the frame and take in the textures and temperatures of the space.

The aim of adopting a term like material-specificity is not to neglect the overall properties or history of the site itself, but rather to establish a tangible link between the body and the location. In order to develop screendance that is rich in cinematic sensations and choreographies that are intricately linked to the ground, I propose this shift in focus. If a dance created for a beach can be lifted and re-set on a different beach, it is not adhering to the original meaning of the word site-specific. What we are witnessing is a dance that one could call material-specific, one where the dialogue between sand and dancer produces a narrative that will be captured by the camera.

In the following selection of films, natural materials such as light, sand, dust, salt, moss, snow, and water become sources for movement and catch the eye of the camera. In 
the tradition of Body Art and Butoh, building off of the work of such artists as Ana Mendieta (Silueta Series 1973-1980), Eiko and Koma, Amy Greenfield, and Anna Halprin, the following films integrate natural materials into their choreography, relishing this newfound textural richness. As we move from hard to soft grounds, from more stagelike surfaces to liquid settings, we observe how the camera zooms in on details making bare skin appear vulnerable. Bodies give into the horizontality of landscapes and embrace the contours of the ground, while the camera looks for that point of collision between surfaces.

\section{Horizons of Exile (2007) - Between Sand and Salt}

Spanish-British artist Isabel Rocamora shot her 2007 film in the Atacama desert in Chile, one of the most arid places on Earth. Looking for a timeless desert landscape, she chose a location with geysers, a salt marsh, sand dunes, and a sharp horizon line. Despite working at very high temperatures and with blinding sunlight, Rocamora manages to convey a soothing, open landscape. The film, described on her website as "loaded with affect," "presents its politics through a sparse dialogue between human and landscape." ${ }^{23}$ Two veiled women dressed in black roll, walk, and rest on the ground. The vast space around them implies they have nowhere to go, matching the film's theme of exile. Deborah Jowitt in her review of the film in the Village Voice sees these women "slowly rolling and twisting in the barrenness ... express with great economy both the pain of leaving and the pain of staying." ${ }^{24}$ The emotional content of the film is carried primarily via excerpts of interviews of exiled Iraqi and Kurdish women, which are layered onto the desert scene. The pain we hear on the soundtrack matches the material roughness of the ground. As the women cross the hot, dry, and coarse space in a slow and steady manner, the emotional and physical weight becomes heavy.

While the physical space serves as a metaphor for exile, the choice of geographic location is puzzling. The connections between the Chilean desert, the veiled dancers, the displaced Iraqi voices, and the Armenian duduk flute on the soundtrack are not immediately evident and create tension within the work that serves to dislocate the site. ${ }^{25}$ For journalist Ferran Mateo, the Chilean location is "the most obvious estrangement in the work, in the contextualizing of dancers with place." He explains that it "emerged as an imperative following the Lebanon/lsrael conflict and the instability of the region post 9/11. As a work funded by the Arts Council of England, the ministry of culture advised the artists to move the film's production away from Petra (the original shoot location), making a virtue of necessity. ${ }^{26}$ If the film uproots the location to accommodate the practicalities of the shoot, the connection between these powerful narratives, their choreographic embodiment and their setting becomes compromised. Therefore, in this film, as the artist herself states,"the location looses its identity and becomes a stage, a hypothesis, fiction, poetry, metaphor...." ${ }^{127}$ 
The site-specificity of the film remains to be found in its material connection between the women's clothed bodies and the harsh terrain.

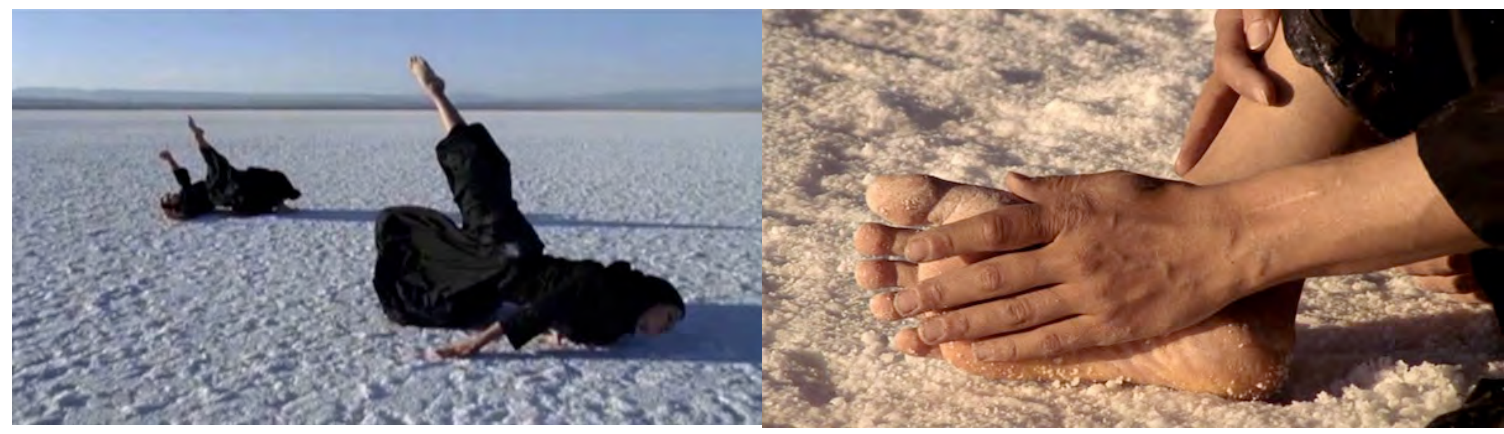

Connecting the body to the ground; screenshot from Horizons of Exile.
Coarse ground against the extremities; screenshot from Horizons of Exile.

\section{Prélude à la Mer (2009) - From Water to Dust}

Shot in October 2009 in the Aral Sea in Kazakhstan, Thierry de Mey's film takes place in a former lake, now dried up due to climate change. Featuring the choreography of Anne Teresa De Keersmaeker set to Claude Debussy's Prélude à l'après-midi d'un faune, two dancers seem lost in the desert, encountering only each other and the dryness of the ground. In the wide-open space, the sharp contours of the dancers' bodies create a jarring contrast. Camille Guynemer describes how the inescapable horizon line and the vastness and stillness of the space create a type of hyper-visibility of the dancing bodies. ${ }^{28}$ Similarly, Walon suggests that the endless tracking shots showcase this "lack of landmarks, and the boundless, empty horizon provokes a feeling of disorientation and a sort of lateral, spatial vertigo." ${ }^{29}$ The viewer gets lost in the proportions and scale of the site, expecting to find not only narrative in the dancing bodies, but also spatial anchors.

Amidst the immensity of the location, and the overwhelmingly powerful music, de Mey manages to create a sense of texture and intimacy through moments of stillness and silence captured in visual and aural close-ups of the body as it meets the ground. ${ }^{30}$ For Walon, the fact that "the dancers-who represent two fauns-are solidly grounded on the floor as they walk on all-fours, roll-up, and rub their bodies on the sandy expanse, suggests, especially through the sounds produced by these contacts, the roughness and dryness of the site." ${ }^{131}$ As their limbs scrape the salty and dusty surface of the land the camera catches the tension through frequent close-ups. The blinding light casts sharp shadows marking the soil with another trace of their incongruous bodies. This is a no-man's land par excellence. Where there once was a sea, there now are these two bodies skimming the soil like fish out of water. This 
environmental story of disappearance is found in the tactile link between skin and dust: the water has gone and soon, too, the bodies will vanish.

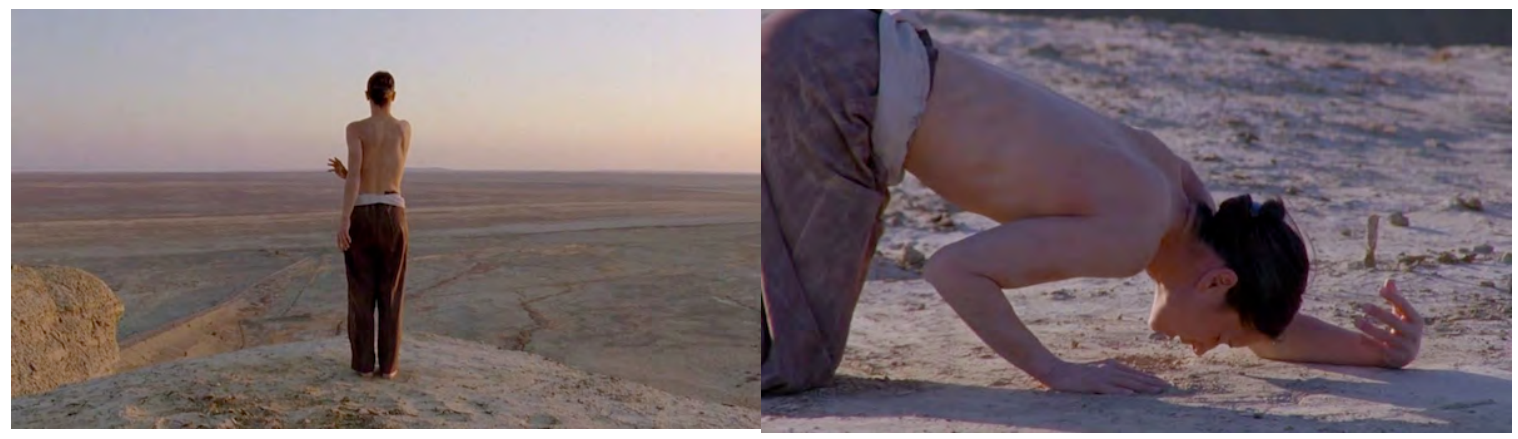

Silhouette against horizon line; screenshot from Prélude à la Mer.

Skin against dust; screenshot from Prélude à la Mer.

Menuett (2011) - Moss

Set in a peat marsh in Malax, Finland, Jukka Rajala-Granstubbon's film begins with an inter-title that explains that when the traditional French minuet arrived in Finland it suited the Finish "forest" people well though it allowed only the hands to touch. The text draws our attention to tactility before we discover any images. The film opens on a close-up of moss and two bare feet step into it gently. The material comes first, the body second. A leg extends into the frame and leads us into this landscape filled with rich textures. The face of a female performer appears from behind a tree branch, keeping nature in the frame as much as the human body.

Four dancers come together to perform a modified minuet. This wild setting immediately seems unusual for such a formal dance yet it incorporates the local textures through close-ups of bare feet sinking into the ground. The two couples playfully dance, at times letting themselves fall backwards into the soft moss, their linen costumes becoming damp. The sounds of the squishy ground and the visible traces of its moisture on the costumes of the dancers draw the viewer's attention to the substance: through its material properties this landscape absorbs the dance. Mia Wiik's choreography incorporates frequent moments of touch between the dancers, moving beyond the boundaries of the traditional minuet, as if the invigorating setting triggered tactile explorations. Heads lean against each other, hands meet, and shoulder blades rest on their partner's back. On this spongy earth the body can fall without harm, feet sink in with joy and the "forest" people seem at home. By transposing a minuet to a peat bog the film pushes the choreography to exploit the new absorbent ground and develop a dance with a material that triggers a sense of tactile freedom and lets the body move with ease. 


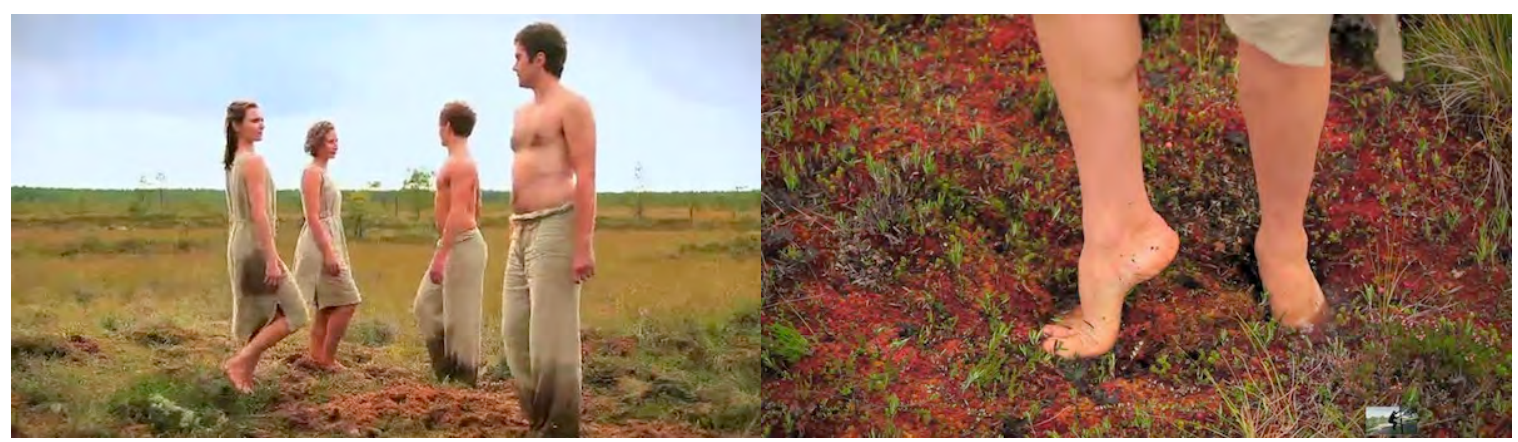

Wet clothes and traces of the ground on the body; Textures for tactile exploration; screenshot from screenshot from Menuett. Menuett.

\section{1/6 D'après Obvie (2010) - Snow}

Out of the series of six solos choreographed by Cindy Van Acker turned into six films by Orsola Valenti, the most material-specific is 1/6 d'après Obvie, set in a snowy field in the mountains of Switzerland. The opening shot is blurry, the falling snow makes the sky almost indistinguishable from the ground. Against this white background, a body clad in black snow gear rolls slowly on the ground, appearing hyper-visible in this monochromatic environment. In this sea of white, our only anchor is the dancing body. As if rolling down a hill, the performer immerses her body in the material, like a child making snow angels. The choreography resembles a floor warm-up routine where the body slowly grows out of the floor, lifting sometimes a leg, sometimes an arm. As she moves slowly and continuously across this powdery texture, the snow clings to her clothes, accumulating in the folds of the fabric, creasing audibly. The use of direct sound captures the crunch that her body makes when it touches the ground and penetrates the material. An establishing shot reveals the solitary body in the landscape while a series of tighter close-ups focus on the imprint of her body on the snow. Rolling around in place, she marks the ground with her pelvis and back, creating a temporary dent in the thick substance. The falling snow flakes remind us that her trace will soon be covered, and the landscape will regain its pristine appearance.

The dancer rolls onscreen from left to right, as the camera alternates between long, medium, and close-up shots, producing the illusion of accelerated movement on a flat surface. She covers ground and the ground covers her in snow. The faint string music washes over the image in a continuous drone, smoothing over the editing cuts. The high pitched sound gives her limbs lightness against the heavy bulk of the snow. The image fades to white and returns to the same site this time with the performer in close-up quasi-naked, wearing only nude underwear. This dreamlike scene works like an $\mathrm{x}$-ray: it reveals the sensations of the body, making the same movements as before appear vulnerable and restrained. As the dancer rolls with apprehension, her bare skin 
slowly touching the frozen snow, each weight shift generates tension in the viewer. The body seems delicate and fragile in this climate: her exposed face, arms, inner thighs and breasts come in contact with the snow and make us cringe. In this scene, the haptic image renders temperature first and texture second. The dancer, whether clothed or not, always stays flat on the ground, never coming off entirely until the end when she gets up and walks into the distance, her dark silhouette blending with the dark greens of a distant pine forest. By rooting the choreography on the ground, the dance becomes about snow. The body never leaves the material and embraces it despite its temperature.

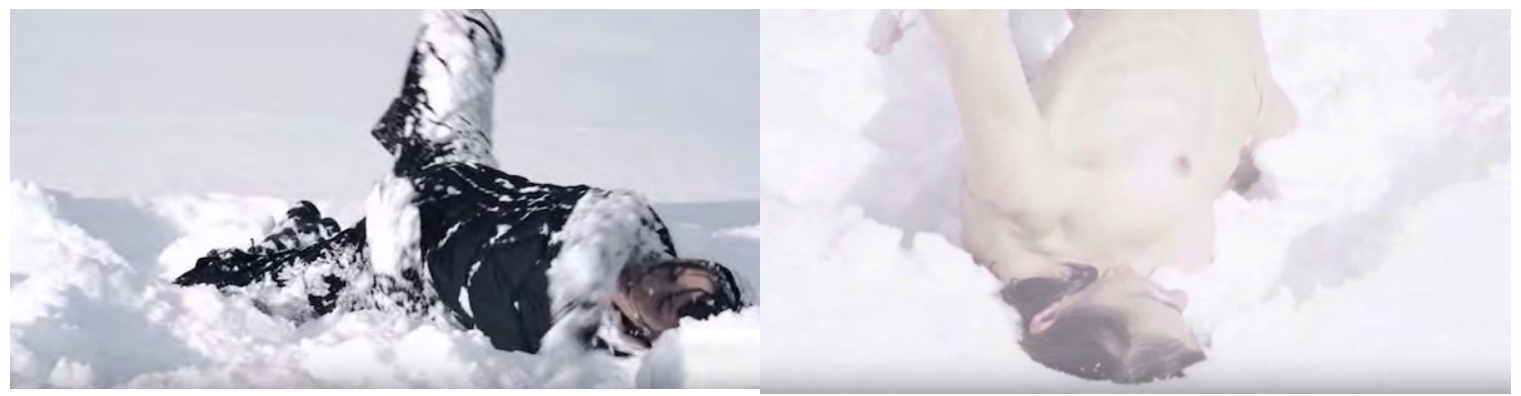

Snow clings to clothes and adds texture and sound Cold material makes skin seem vulnerable; to the body in motion; screenshot from $1 / 6$. screenshot from $1 / 6$.

\section{Blush (2004) - Water}

Shot off of the coast of Corsica, France, and in the back-alleys of Brussels, Blush by Belgian filmmaker and choreographer Wim Vandekeybus, stiches together two territories to create a wild, frenetic, sexual, rock-music scored film that pushes dancers to their limits, especially outdoors. Among other materials, Blush makes explicit use of water, pioneering the use of underwater cinematography in screendance. Several scenes in the film use water to disburse the energy of the choreography. As a group of dancers perform highly energetic partnering sequences in a clearing between dry Mediterranean trees, the filmmaker intercuts shots of other dancers jumping into the nearby ocean. Elsewhere, a group of women dip into a nearby river, and come out to dance on its sandy bank, soaking wet, the sand clinging to their bare legs. Near a small waterfall, a female dancer squats like an animal at a watering hole. An extended sequence shot underwater shows women swimming like mermaids, their skin glistening in the sun. A couple dressed in bright red dance together in the sand in a sort of aggressive swing dance, until the female dancer is flung into the ocean, where she floats face down momentarily until another man comes to snatch her back out. A woman wearing a long white dress walks on the edge of a cliff, before falling into the water. She is later shown walking through the water, near the shore, the fabric of her clothes now transparent, seemingly struggling to stand, and falling back into the waves. 
Throughout the film, each time a sequence takes place on the ground, Vandekeybus cuts back to the water. It is as if the materiality of the water serves to diffuse the high energy of the overall choreography and fast-paced editing. Incorporating long shots of cliffs, close-ups of the surface of the splashing water and underwater cinematography, this film exploits the power and beauty of the material. Absorbing the weight of these hyper-active bodies, the surface of the ocean coaxes the dancers into its depths. When jumping back out and darting across the land, their skin remains wet and their costumes clings to their bodies. The wetness appears invigorating, as the dancers move fearlessly through the different settings. Without water Blush would lack balance. Vandekeybus's incorporation of it in his choreography demonstrates the potential of screendance to work with new materials. The body landing with a splash and the shimmer of water left on the skin give the film a texture to showcase, a temperature to convey, and a sound to record that gives the body weight and substance.

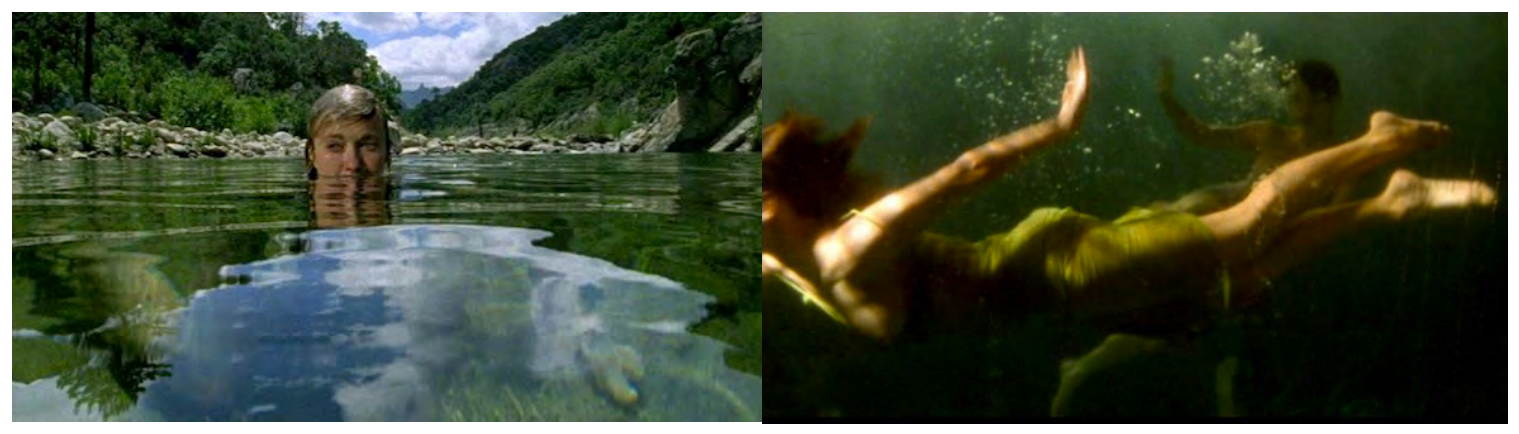

Dancers emerge from the water, giving importance Shooting underwater and its impact on movement; to its surface; screenshot from Blush. screenshot from Blush.

\section{Conclusion}

Whenever I quiet this persistent chatter of words within my head, I find this silent or wordless dance always already going on - this improvised duet between my animal body and the fluid, breathing landscape that it inhabits.

- David Abram ${ }^{32}$

By shifting our focus from site-specificity to material-specificity this article proposes new strategies for listening to space in order to avoid taking the locations in screendance for granted. Different artistic approaches exist to ground the body in space, to make site more than a backdrop, and the one proposed here has been to make material-specific screendance. This concept urges us to dig deeper into the nuances between different theories of site-specificity in the arts. Its application aligns 
screendance with other visual and performance art forms that are based in the manipulation of raw materials such as painting, sculpture, Land Art, installation art, or architecture. The limited scope of this article prevents me from developing this material catalogue further but one could begin to curate, teach, or design films around the concept of a specific material. Could one imagine a screendance for clay, wax, JellO or Styrofoam? Curating a series of films designed for snow, for example, would not only give an audience the opportunity to explore the range of motion possible within a chosen environment, but also the scope of choreographic strategies created by the artists.

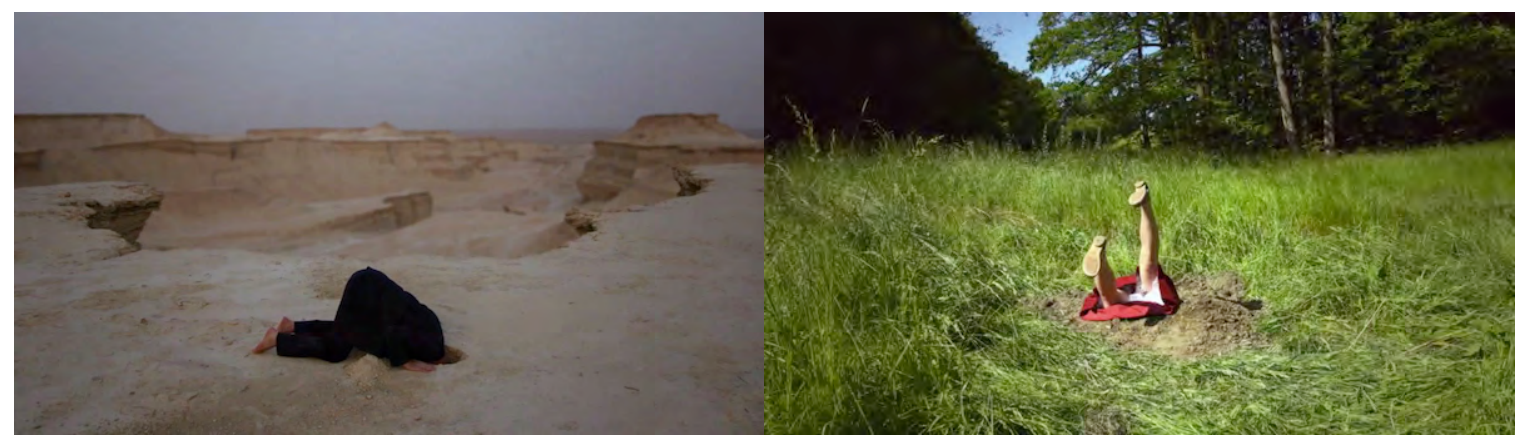

Digging in; screenshot from Nation for two.

Finding meaning and movement in the materials; screenshot from Nation for Two.

In practice, the concept of material-specificity exploits what makes screendance shot on location so different than work made for the stage or studio, namely its ability to incorporate natural materials in order to connect the body to its surroundings. The recent film Nation for Two by Nir Nadler and Chaja Hertog (2012) does precisely this by creating a stop-motion film that begins with two bodies digging their way into the ground towards each other. The film does away with bodies for a while, capturing only a supposed trace underground as they move through different landscapes, freely crossing geographic borders. Each shot presents a different material and as the film cuts from grass and dust to water and sand via bricks, leaves, concrete, salt, and rock, viewers become enraptured in this journey across textures, in these haptic images full of touch and ruffling sounds. As screendance continues to explore this dialogue between the (animal) body and the (breathing) landscape it inhabits, as David Abram would say, I look forward to films that experiment with ambient sound, sparse music, voiceover, or dialogue as well as shots without bodies. I am eager to see screendance resist the urge to fictionalize the landscape. After all what impact on the land does the screendance community wish to have? What do we take from it, but especially what do we bring to it? 


\section{Biography}

Sylvie Vitaglione is a PhD candidate in the Department of Cinema Studies at New York University. Her chapter "Surface Tension: Experimental Dance Films And The Undoing Of Urban Space" is forthcoming in May 2016 in the anthology Imaging the City: Art, Creative Practices and Media Speculations, with Intellect Books. Vitaglione has been an adjunct professor at New York University, The New School, Queens College and the College of Staten Island. She has taught Film History, Film Theory, and seminar classes on Choreography and the Moving Image, Music Videos and Agnès Varda. She has programmed screenings, panel discussions and workshops on the Tiny House movement, definitions of experimental film, Chantal Akerman's film "One Day Pina Asked" and dance and documentary form for New York University, Gibney Dance Center and Dance Films Association in New York. She trained in ballet and contemporary dance in Monaco, San Francisco, London and New York, and is a certified yoga instructor.

Email: smv259@nyu.edu

\section{Notes}

${ }^{1}$ For discussions of the body in screendance see for example Sherill Dodds, Dance on Screen, 29-36 and 126-169; Douglas Rosenberg, Screendance, 33-73; and Erin Brannigan, Dancefilm, 39-62 and 172-197. Valerie Briginshaw additionally analyzes dance films through their use of public space as a means of discussing the constructions of gendered subjectivities in Dance, Space, Subjectivity.

${ }^{2}$ Bob Lockyer pointed out this new ground when he suggested that "dance made for camera has given choreographers another place to dance. The sprung floor can now give way to a beach, a bar, a school hall, or even a field." He does not explain why one would move outside by rather asks "why not?" See Bob Lockyer. "A New Place for Dancing," 160.

3 Sophie Walon. "Poetic Phenomenology," 30.

${ }^{4}$ Noemie Lafrance has used this term in keynote talks at Experimental Film Virginia in relation to working on site.

${ }^{5}$ Dodds, 123.

${ }^{6}$ Heike Salzer and Ana Baer, "Being a Video-Choreographer," 106.

${ }^{7}$ Salzer and Baer, 106.

${ }^{8}$ Kyra Norman, "In and Out of Place," 14.

${ }^{9}$ Norman, 19. 
${ }^{10}$ Katrina McPherson, Making Video Dance, 67.

${ }^{11}$ Idem., 64.

${ }^{12}$ Idem., 68.

${ }^{13}$ Rosalind Krauss, "Sculpture in the Expanded Field," 41.

${ }^{14}$ Miwon Kwon. "One Place After Another," 86.

${ }^{15}$ Richard Serra, "Tilted Arc Destroyed," 34-47.

${ }^{16}$ Michael Lailach, Land Art, 11.

${ }^{17}$ Ben Tufnell. Land Art, 13.

${ }^{18}$ Kwon, 159.

${ }^{19}$ Idem., 95.

${ }^{20}$ Ibid.

21 "déterminer la beauté intime des matières; leur masse d'attraits cachés, tout cet espace affectif concentré à l'intérieur des choses." Translation my own. Gaston Bachelard. La Terre et les rêveries de la volonté, 9.

${ }^{22}$ Walon, 30.

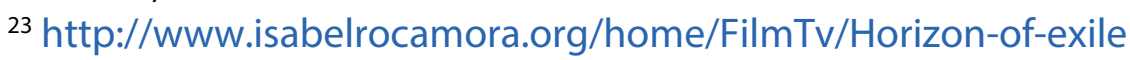

${ }^{24}$ Deborah Jowitt. "Images on the Move," http://www.villagevoice.com/2008-0101/dance/images-on-the-move-for-dance-on-camera-2008/

${ }^{25}$ The Armenian duduk is an woodwind flute that sounds like a cross between a clarinet and an oboe.

${ }^{26}$ Ferran Mateo. "La danza de la liberación" (the dance of liberation). La Vanguardia (Culture Magazine - Screens), 25 February 2009.

${ }^{27}$ Isabel Rocamora, in María Céron. "El gesto humano," 242.

28 "Sur l'horizontalité infinie du sol craquelé de sécheresse, les phrases développées par les danseurs atteignent une lisibilité fulgurante. Cet espace libre, démesurément fixe, démultiplie l'impact de ce qui bouge. Nous ne sommes plus là dans une plongée en son cœur, nous sommes dans un hyper-rayonnement du mouvement". Translation and paraphrase my own. Camille Guynemer in Jean Marc Adolphe, "Thierry de Mey," 5. ${ }^{29}$ Walon, 39.

${ }^{30} \mathrm{I} \mathrm{am}$ using the term aural close-up here to refer to moments when the sound recording moves the microphone in close to capture a sound in greater detail.

${ }^{31}$ Walon, 39.

${ }^{32}$ David Abram. The Spell of the Sensuous, 53.

\section{References}

1/6 D'apres Obvie. Dir. Orsola Valenti, chor. Cindy Van Acker. Switzerland, 16 min, color, sound. 2010. 
Abram, David. The Spell of the Sensuous: Perception in a More-Than-Human World. New York: Random House, 1996.

Adolphe, Jean Marc (ed.). "Cahier Special: Thierry de Mey." Mouvement. (April-June 2011).

Aunis. Dir. Luc Riolon, chor. Jacques Garnier. France, 13 min, color, sound. 1993.

Bachelard, Gaston. La Terre et les rêveries de la volonté. Paris: Jose Corti, 1948.

Blush. Dir. and chor. Wim Vandekeybus. Belgium, 52 min, color, sound. 2004.

Branningan, Erin. Dancefilm: Choreography and the Moving Image. New York: Oxford University Press, 2011. http://dx.doi.org/10.1093/acprof:oso/9780195367232.001.0001

Briginshaw, Valerie. Dance, Space and Subjectivity. New York: Palgrave Macmillan, 2001. http://dx.doi.org/10.1057/9780230508538

Candelerio, Rosemary. "Bodies, Camera, Screen: Eiko \& Koma's Immersive Media Dances." International Journal of Screendance 4 (2014): 80-92.

http://dx.doi.org/10.18061/ijsd.v4i0.4522

Cerón, María. "El gesto humano en lo fílmico. Entrevista a Isabel Rocamora". Arte y políticas de identidad - Revista de investigación. Vol 9, Ediciones Universidad de Murcia, Spain, 2013.

Dodds, Sherill. Dance on Screen: Genres and media from Hollywood to Experimental Art. New York, Palgrave, 2001. http://dx.doi.org/10.1057/9780230509580

Jowitt, Deborah. "Images on the Move For Dance on Camera 2008". The Village Voice. Tue, Jan 1, 2008. http://www.villagevoice.com/2008-01-01/dance/images-on-themove-for-dance-on-camera-2008/

Horizons of Exile. Dir. \& chor. Isabel Rocamora. UK/Spain, 21 min, color, sound. 2007. Kloetzel, Melanie and Carolyn Pavlik (eds). Site Dance: Choreographers and the Lure of Alternative Spaces. Gainesville, FL: University Press of Florida, 2009.

Krauss, Rosalind. "Sculpture in the Expanded Field." October. 8 (1979): 30-44.

Kwon, Miwon. "One Place After Another: Notes on Site Specificity". October. 80 (1997): $85-110$.

. One Place after Another: Site-Specific Art and Locational Identity. Cambridge: MIT Press, 2004.

Lailach, Michael. Land Art. Koln: Taschen, 2007. 
Lockyer, Bob. "A New Place for Dancing." In Envisioning Dance and Film on Video, eds. Judy Mitoma and Elizabeth Zimmer, 156-162. New York: Routledge, 2002.

Mateo, Fernando. "La danza de la liberación" (the dance of liberation). La Vanguardia (Culture Magazine - Screens), 25 February 2009.

McPherson, Katrina. Making Video Dance: A step-by-step guide to creating dance for the screen. London: Routledge, 2006.

Menuett. Dir. Jukka Rajala-Granstubb, chor. Mia Wiik. Finland, 6 min, color, sound. 2011.

Mitoma, Judy (ed.). Envisioning Dance and Film on Video. New York: Routledge, 2002.

Nation for Two. Dir. and chor. Nir Nadler and Chaja Hertog. Netherlands, 15 min, color, sound. 2012.

Norman, Kyra. "In and Out of Place: Site-based Screendance." The International Journal of Screendance. 1 (2010): 13-20.

Prélude à la Mer. Dir. Thierry de Mey, chor. Anne Teresa de Keersmaker. Belgium, 19 min, color, sound. 2009.

Rosenberg, Douglas. Screendance: Inscribing the Ephemeral Image. New York: Oxford University Press, 2012. http://dx.doi.org/10.1093/acprof:oso/9780199772612.001.0001

Salzer, Heike and Ana Baer. "Being a Video-Choreographer: Describing the Multifaceted Role of the Choreographer Creating Screendance." International Journal of Screendance 5 (2015): 102-115. http://dx.doi.org/10.18061/ijsd.v5i0.4446

Serra, Richard. "Tilted Arc Destroyed." Art in America 77.5 (1989): 34-47.

Tufnell, Ben. Land Art. London: Tate Publishing, 2006.

Walon, Sophie. "Poetic Phenomenology in Thierry de Mey's Screendances: Open Corporealities, Responsive Spaces, and Embodied Experiences." International Journal of Screendance. 4 (2014): 28-43. http://dx.doi.org/10.18061/ijsd.v4i0.4529 